DOI: $10.2478 /$ ausfm-2014-0018

\title{
The Body as Interstitial Space between Media in Leçons de Ténèbres by Vincent Dieutre and Histoire d'un Secret by Mariana Otero
}

\author{
Marlène Monteiro \\ Birkbeck College, University of London \\ E-mail: marlene.mdc@gmail.com
}

\begin{abstract}
This essay examines the ways in which the representation of the body in painting is the starting point of a broader reflection on the plasticity of the medium in two French autobiographical films. In Histoire d'un secret (Story of a Secret, 2003) by Mariana Otero and Leçons de ténèbres (Tenebrae Lessons, 2000) by Vincent Dieutre, the body is indeed at the centre, albeit in very different ways. The first is a documentary about the director's mother who died of the consequences of an illegal abortion in the late sixties. She was an artist and her paintings, many of which depict lascivious female nudes, pervade the film. The second is a self-fictional essay that weaves together narrated episodes of the film-maker's story as a homosexual and drug addict with close-ups of Caravaggist paintings which tend to focus on bodies in pain. Whether prefiguring death and embodying the absent body through the latent evocation of maternity in the first case, or looking back into figural art in the second, both films point to the plasticity of the medium through the representation of matter, that is, paint and, ultimately, the body. The way in which both film-makers resort to light, the close-up, and, as far as Dieutre is concerned, the diversity of film formats, embodies what Deleuze defines as the haptic gaze to explore cinema's own materiality. In addition, the presence of the paintings introduces the issue of intermediality which modestly points to a mise en abyme of the broader question of cinema's shifting ontology.
\end{abstract}

Keywords: body in painting and in cinema, haptic gaze, intermediality, Vincent Dieutre, Mariana Otero.

In his self-fictional essay film, Leçons de ténèbres Vincent Dieutre ${ }^{1}$ embarks on a journey across Europe, from Utrecht, to Naples and Rome, in which he undertakes

1 Vincent Dieutre, born in 1960, is a French film-maker whose work is often described as pertaining to Queer cinema. His films tend to be constructed like self-fictions in which he intertwines stories about his homosexuality and his former heroine addiction with images of - often derelict - urban settings. Leçons de ténèbres (France, Les films de la croisade, 2000) is his second feature length film. 
a sensory exploration of Caravaggism, and successively meets two men. From the voice over narrative, the viewer understands that the first is his partner who joins him on the trip, while the second is a stranger encountered in a gay cruising park of Naples. Throughout the film, Vincent, alone or accompanied, visits museums and churches so that paintings, many of them depicting Christian scenes of the Passion, are omnipresent.

On a rather different note, Mariana Otero's ${ }^{2}$ Histoire d'un secret is a personal film about a childhood trauma of which she has no recollection: the death in 1968 of her mother, Clotilde, an event that remained buried under secrecy and lies for over twenty years. The film-maker only discovered the truth in her thirties, when her father eventually confessed that Clotilde had died of the consequences of an illegal abortion. She had been a painter and as a result, Otero gives her mother's work a prominent place in the film. Coincidentally, a significant proportion of these paintings represent human bodies, notably female nudes.

This essay seeks to explore, through these two case studies, the significance of the paintings and the ways in which their presence in the films contributes to emphasising the materiality of the medium. A preliminary hypothesis is that this process takes place via the physicality of the body. It thus not only enhances sensory affect and haptic vision, but also underscores intermediality, which ultimately points to a reflection upon cinema itself. If the comparison of these two films may come across as rather eclectic, the juxtaposition of their differences and similarities proves extremely useful. Indeed, despite and beyond their specific and very different narratives as well as aesthetics, both films point to similar questions about sensation in relation to cinema and art in general, while showing how the body works as a conduit for sensory perception.

\section{Bodily Presence}

\section{The Body in Pain}

The paintings appearing in Dieutre's film include pieces based on biblical scenes, such as Guido Reni's David with the Head of Goliath (1605, Musée du Louvre, Paris); or on Greek mythology, such as Dirck van Baburen's Prometheus Being Chained by Vulcan (1623, Rijksmuseum, Amsterdam). Yet, not only do Christian

2 Mariana Otero, born in 1963, is a French documentary-maker. Unlike Dieutre, whose work is almost entirely centred around his persona, Histoire d'un secret (France, Archipel 35, 2003) is Otero's only film so far focused on a personal issue. 
scenes seem predominant, but the religious connotation is also explicit for the film's title, Tenebrae Lessons, refers to the lessons based on the Old Testament's Book of Jeremiah which are sung in Church during the Holy Week. To give a few examples, the film opens on a close-up of Caravaggio's Christ at the Column (ca. 1607, Musée des Beaux-Arts, Rouen); later, we see a still, full screen shot of Gerrit van Honthorst's Saint Sebastian (1623, National Gallery, London), and one of Dirck van Baburen's Crowning with Thorns (1623, Catharijneconvent, Utrecht). But Vincent's interest is not restricted to painting: as he wanders in the Church of Saint Cecilia in Rome, the camera also lingers on the statue of Saint Cecilia's Martyrdom by Stefano Maderno (1599-1600, Chiesa di Santa Cecilia in Trastevere, Rome). In other words, these works tend to focus on suffering and violence.

From a narrative point of view, this depiction of pain enhances Dieutre's expression of his own suffering and existential malaise as a homosexual addicted to heroin and surrounded by friends dying of drug overdose and/or AIDS during the early 1980s. As for Clotilde's paintings in Otero's film, it is hard not to see in the curvy nudes an implicit hint at maternity and, by extension, an unwitting metaphor for her own undesired pregnancy. As such, the paintings thus bear the hidden clues of her untold pain and agony as a result of her failed abortion [Fig. 1]. The expression of pain and suffering contributes to emphasising the presence and material reality of the body. In keeping with this, Georges Canguilhem writes that for the ill person, "the state of health is the unconsciousness in which the subject is of his own body. Conversely, the consciousness of the body arises from feeling the limits, the threats, the obstacles to health" (Canguilhem 1993, 52, my translation). Doleo ergo sum, as it were, "I suffer therefore I am," for pain asserts the reality of existence. This is particularly significant for Dieutre - and homosexuals at large - as he strives to assert his place in the world, having been "hidden and invisible" (Dyer 2002, 15) for years: to stress suffering thus grounds him in the reality of existence.

Yet, Canguilhem's point has some relevance in Otero's case as well. Obviously, what is at stake here is not Clotilde's consciousness of her own body for she is dead; but her suffering, which is implicitly relayed by the paintings and their materiality, harks back to the reality of her existence, of her having-been-there, by opposition to her death which may have seemed unreal to Mariana and her elder sister Isabel. And indeed, we learn early in the film, that the family first told them that Clotilde was simply working in a different town. It is only a year later that their grandmother, faced with Isabel's insistent questioning, eventually admitted that she was in fact dead. In other words, it was as if Clotilde had not 
died but merely vanished. Mariana thus feels the need to make her mother's life (and death) real and visible and endeavours to bring her body back to the surface - metaphorically, that is. In this sense, the film's final sequence which stages a public exhibition of Clotilde's paintings certainly acts as an exhumation of her body in lieu of the mourning ritual that the daughters were denied.

\section{Erotic Bodies}

Clotilde's paintings convey stark erotic presence, which necessarily points to the physicality and sensuality of the body. At one point in the film, a conservationist examines the paintings and notes Clotilde's particular predilection for the representation of female flesh and pubic hair, which constitutes a landscape in its own right, as she puts it. George Bataille posits that the difference between a "simple sexual activity" which consists of reproduction and eroticism is a "psychological quest independent of the natural goal" (Bataille 1986, 11). In this sense, the abortion that led to Clotilde's death comes across as a marker or sign of eroticism as prefatorily defined by Bataille, that is, as "assenting to life up to the point of death" (ibidem). This is also in keeping with Dieutre's representation of eroticism, which is necessarily envisaged from the angle of his assumed, exposed and expressed homosexuality. In his film, the intertwining of his personal story (narrated in voice over) with images of Caravaggist painting presents eroticism as inherent to suffering.

Furthermore, the religious motifs painted by Caravaggio also contain for Leo Bersani and Ulysse Dutoit a certain degree of eroticism. Commenting on his Calling of Saint Matthew (1600, Chiesa San Luigi dei Francesi, Rome), they argue that the artist "proposes continuities between what we would ordinarily think of as vastly different categories of experience: the erotic come-on and Christ's summoning his future disciple to follow him" (Bersani and Dutoit 1998, 26). To put it differently, Caravaggio introduced humanity - in its most physiological and worldly aspects - into the religious motif. As far as Caravaggism is concerned, the erotic charge is also manifested through the contrast between suffering and pleasure, both located in the physicality of the body. Yet it also emanates from the intrusive and insistent gaze of the camera's close-ups on body parts in the paintings [Fig. 2]. Like images stolen at a glance, these close-ups provide a fragmented representation of the body, thus evoking sensation more vividly. 


\section{The Haptic Gaze}

As a result, many elements in both films seem to be working towards emphasising the physicality of the body and, by extension, matter. For Dieutre, the Caravaggesque mode of representation becomes a starting point for his own personal sensory explorations within the moving image. As for Otero, it partakes perhaps less of a self-conscious aesthetic choice than of a desire to touch her mother, as it were, not only through her paintings but also through the process of film-making, by way of the haptic gaze, for instance. On a formal level, the use of light and the close-up in particular partake of this attempt to produce a tactile image.

\section{Chiaroscuro}

Dieutre makes an interesting use of the Caravaggist chiaroscuro. The film is almost entirely shot at night or indoors so that the light always comes from an artificial source. Just after the opening sequence, Vincent appears in a dark room or in what resembles a shooting studio; the only source of light comes from a small light projector (held by a technician), which hovers back and forth over and around his naked torso: light is thus mobile. [Fig. 3.] The projector's movements are entangled with those of the handheld camera. The chiaroscuro thereby created sculpts the body and echoes Caravaggesque representations of the body, while enhancing the haptic gaze. Similar sequences in which Vincent is filmed with another man are dispersed throughout the film like extra-diegetic moments. However, if light is often said to emanate from a divine source in Caravaggesque painting, here it appears as a diffuse expression of emotion caused by the sensation of the bodies.

In Otero's film, one sequence strongly resonates with Dieutre's chiaroscuro scenes: a lateral tracking shot of the street at night, filmed from inside a car, reveals in low-angle the succession of light beams from the street lamps. After a cut, a painting by Clotilde (a female nude) appears on screen; it is placed inside the car, thus intermittently illuminated by the passing lights so that a streak of shadow keeps going back and forth over it [Fig. 4]. The lighting creates amber shades which underscore the skin's colour in the painting. At the same time, it also creates a chiaroscuro setting whose emotional charge takes on a melancholic tone, just as in Dieutre's Leçons. In his book L'attrait de la lumière (The Attraction of Light, 2010), Jacques Aumont describes a scene in Ordet (The Word, Carl Dreyer, 1955) in which a dark living room is illuminated by car lights through a window on the side, while a woman is agonising in the room next door. For Aumont, this 
light is Death passing by and he adds that "it suggests to us a figure of light - and 'figure' here is to be understood in its full meaning, that is, of figura, of modelling and intentional artifice" (Aumont 2010, 47). In a similar way here, death and the secret that characterise Clotilde's story are suggested through a figure of light, whereby the chiaroscuro, as intentional artifice, models and physically marks the body in the painting.

\section{The "Tactile Close-up"}

To come back to the close-ups briefly mentioned above in relation to eroticism, both films similarly display the paintings in extreme close-up as if the camera were trying to penetrate inside the canvas, as if the image had depth. In Histoire d'un secret, as the conservationist thoroughly examines Clotilde's paintings, she scrutinises the canvases' quality and size, then starts to analyse their preparation and the painting technique. She infers from her observations that Clotilde seemed much more interested in paint and colour than in the precision of drawing, and that she probably used thick applications of paint and vigorous strokes while the shapes are vague and suggested, rather than accurately outlined. In other words, Clotilde's painting technique emphasises texture. The woman's explanations are intertwined with close-ups on the canvases, which reveal their pattern as well as the thick texture of the brushstrokes [Fig. 5]. As a result, Clotilde's technique and Mariana's close-ups coalesce into matter and physicality, one sustains the other; and as Béla Balázs puts it, "the magnifying glass of the cinematograph brings us closer to the individual cells of life, it allows us to feel the texture and substance of life in its concrete detail" (Balázs 2010, 38).

During her observations, the conservationist regularly runs her fingers along the contours and lines of the paintings, as if to enhance her comments, thereby re-enacting by the same token Clotilde's own gestures over three decades earlier, in an attempt to understand, almost like a detective, how the painter may have proceeded [Fig. 6]. Similarly in Leçons de ténèbres, Vincent runs his hands along the contours of a painted body. Later in the film, he transposes these gestures from the paintings onto his own images, onto his lover's face for instance [Fig. 7]. Laura Marks's expression of "tactile close-ups" (Marks 2000, 172) is very appropriate here. In fact, Otero and Dieutre's tactile close-up brings the viewer extremely close to the surface and even gradually becomes literal touch. However, if the term "tactile" in Marks's expression may appear as synonym with haptic, it seems to be understood instead as partaking in the broader spectrum of what she 
describes as haptic visuality. In addition, the expression also serves the purpose of spelling out the property of such visuality which "functions like the sense of touch" and in which haptic images "engage the viewer tactilely" (Marks, 2000, 22). Similarly, in the films described here, the hands and finger gestures come across as a way of making explicit and magnifying the sense of touch inherent to the films' haptic images. After all, the fingertips are nothing but the index itself and as modelling tools, as it were, they are constitutive of the Figura as defined by Erich Auerbach, that is to say, in very simplified terms, the cavity of a mould or an imprint. ${ }^{3}$ Let us not forget either that Peirce defined the index in terms of physical connexion - and not mere analogy. Interestingly enough, Otero shows seven black and white photographs of her mother in the film, which follow one another in full screen mode and stand outside the diegetic space, by contrast with a scene in which the characters would have held them and looked at them. All are group photographs so that the viewer is not even sure if Clotilde is present in them. As a result, their iconic and indexical property is undermined and fails to satisfactorily evoke Clotilde to Mariana who cannot remember her mother, not even what she looked like. Hence the paramount significance of the paintings, for they are the only physical link, through their tactility, with Clotilde. As a result, touch establishes here a connexion, via the figure and the index, between pictorial and filmic images, as well as between mother and daughter. ${ }^{4}$

\section{Seeing Through the Skin}

Balázs also argues that the close-up can reveal details that the normal eye does not see, "it exposes the face beneath the surface" (Balázs 2010, 103). This resonates strongly with Mariana's search for traces of her mother, as the close-ups on the canvases look like an attempt to uncover the secret, to detect the hidden detail beneath the surface. Throughout Dieutre's film, we also see recurrent images of pierced bodies, starting with the different representations of the Christ's own body as well as that of Saint Sebastian pierced by arrows, as in Gerrit van Honthorst's Saint Sebastian, cited above, or in Saint Sebastian aided by Saint

$3 \quad$ Against all odds, finger and figure have a different etymological origin, despite the apparent resemblance of the former with the Latin root (fingere) of the latter. Finger stems from common Germanic and, while its pre-Germanic antecedent is uncertain, the word tends to be related to the root of the number five. See The Oxford English Dictionary (1991, 932).

4 Of course, the paintings also point to artistic creation as another level of connection between mother and daughter. 
Irene (Trophime Bigot, ca. 1620, Pinacoteca, Vatican). It is as if the camera were also trying to penetrate the canvas and the body, by extension, to check out its mechanics inside, akin to a doubting Thomas sticking his finger inside the wound of the resurrected Christ. ${ }^{5}$ Similarly, Otero is very explicit about her intentions in this respect for she writes in the film's script that, thanks to editing, she wants us "to 'enter' in the painting" (Otero 2006, 91).

This, in turn, raises the question of the surface and, most importantly, of its depth. The attempt to see through the skin of the image harks back to Jacques Rancière's criticism about the surface as ontologically bi-dimensional: he argues that the pictorial surface is not a mere "geometric composition of lines," but also corresponds to a certain distribution of the sensible (Rancière 2004, 15). Rancière adds that it should not be opposed to depth, but rather to the living that is, to the living act of speech. The point here is certainly not to argue instead that pictorial and film images are necessarily or ontologically three-dimensional. More important is the fact that these cuts in the surface, as attempts to look beyond the surface, seem to underscore the notion of passage - from one surface to another for instance - which bears some common traits with Rancière's idea of different forms of expression being combined, such as "the intertwining of graphic and pictorial capabilities" (idem) which took place in the Renaissance. For him, such movements "inspired a new idea of pictorial surface as a surface of shared writing" (idem). In keeping with this, the passage through the surface described above draws attention to the combination of different media as a surface of "shared writing," or in this case, of shared filming.

\section{In-between Media}

\section{Intermediality as a Figure of Sensation}

While the images of pierced bodies mentioned above certainly elicit emotional and physical reactions, the endeavour of both film-makers - and Dieutre perhaps more explicitly - also denotes a fascination for the medium and its materiality. In other words, it is not only the blood and/or the erotic gaze in close-up which cause sensation, but also the passage from one state to another, as well as from one form to another. Sketching a line between Tom Gunning's cinema of attractions and Gilles Deleuze's logic of sensation, Eivind Røsaak reminds us that the figure

5 See for instance the Caravaggio's version, The Incredulity of St Thomas, (1601-1602, Sanssouci, Potsdam), even if the painting does not appear in Leçon de ténèbres. 
of sensation arises in the in-between (Røsaak 2006). Deleuze argues indeed about Francis Bacon's painting that the sensation lies between figurative representation and abstraction. ${ }^{6}$ As for Gunning, as far as early cinema is concerned, sensation is related to the medium and to the passage from stillness to motion. For Røsaak, this space between stillness and movement is "an emotional space [...] where the audience is transported from the familiar to the unfamiliar, from the canny, to the uncanny. The emotions are specifically linked to the appearance of motion, which transforms the emotion into a state of shock." $(2006,322)$. Yet, as he examines the time slice effect in a sequence of The Matrix (Andy \& Lana Wachowski, Warner Brothers, US, 1999), Røsaak posits that new technologies have somehow reversed the process so that the emotional shock, while it still arises in the in-between, emerges this time in the passage from motion to stillness, used as we are today to movement and speed. His argument is also interesting in that it emphasises the relevance of the medium specificity combined with the notion of passage from one state to another, in other words: in-betweenness.

Something of that order seems to be happening in Dieutre's film, as our gaze is caught upon static camera shots, which break the flow of the handheld camera movements to reveal an empty backstreet, a wall, scenes of a city at night, or the still image of a painting. The viewer's emotion thus arises in the passage from the moving film image to the delayed moment of contemplation of pictorial and picturesque - in the etymological understanding of the term - images. ${ }^{7}$ Yet, Bellour's pensive and/or Mulvey's possessive spectator has somehow given way to a bewildered one. Moreover, the uncanny or the sensation effect does not merely come from the stilled moment of contemplation, it is also linked to painting. In the introduction to her book Cinema and Sensation, Martine Beugnet describes the opening scene of Leçons de ténèbres in which Vincent faints in a museum after looking at Caravaggio's Christ at the Column. Dieutre himself described this reaction in an interview ${ }^{8}$ as the physical consequence of the power that painting can have on a human being, while Beugnet rightly argues that it

$6 \quad$ Deleuze in fact attributes this idea to Bacon himself who speaks of sensation as among other things - the passage "from one 'order' to another, from one 'level' to another, from one 'area' to another.” (Deleuze 2003, 36.)

7 See in this respect Laura Mulvey, Death 24x Times a Second, (London: Reaktion Books, 2006), especially Chapter eight: Delaying Cinema, 144-160. Her point whereby new technologies have redefined our modes of viewing is particularly pertinent here: when looking at Leçons de ténèbres in fast forward mode, the contrast between the flowing of the moving images and the pauses on the paintings and other "picturesque" shots becomes particularly striking.

8 Vincent Dieutre, Interview with Pascal Bonenfant, in Leçons de ténèbres, bonus track of the DVD release (2004). 
points to a "sensory awareness" and that "to let oneself be physically affected by an art work or a spectacle is to relinquish the will to gain full mastery over it, choosing intensity and chaos over rational detachment" (Beugnet 2007, 3). This emotional shock could also be understood as a manifestation of the abject in the sense that Julia Kristeva ascribes to it: the "abject, [...] the jettisoned object, is radically excluded and draws me toward the place where meaning collapses" (Kristeva 1982, 2). Vincent is drawn to the painting, but at the same time - or because? -, he is confronted with an emotion that he cannot comprehend and which is beyond rational meaning. His collapsing is thus due to his attraction for something whose overpowering effect he cannot rationalise.

\section{Involvement with the Medium}

Vincent's wanderings throughout the city at night allow him to play at recreating typically Caravaggesque settings and motifs, as he films the cities' poor areas, or the frenzy of urban nightlife. At one point, he buys smuggled cigarettes from an elderly woman and a younger man - both presumably homeless. The transaction takes place in a street corner of Naples around a fire, so that the light comes from the flames, at the centre of the image. On other occasions, Vincent and his partner are sitting in busy, dimly lit restaurants. In one such sequence, Vincent's partner takes the candle from the table and holds it above the menu while they talk to the waiter. Such mises-en-scène are redolent of the numerous Caravaggesque representations of players, drinkers, and other revellers sitting around tables in taverns. Finally, Dieutre also makes connections by juxtaposition, through editing, between scenes he films and the paintings. Drawing from Laura Marks, Martine Beugnet argues that the effect of such mimesis is a sign of involvement with the object of the gaze, and this, in opposition to the world of abstraction. Marks adds that "through mimesis we can not only understand our world, but create a transformed relationship to it - or restore a forgotten relationship" (Marks 2000, 141). This last remark could not apply more accurately to Otero as she strives to restore her forgotten relationship to her mother by also miming the latter's painting through her own film-making. The film's recurrent panoramic tracking shots of Normandy's countryside echo Clotilde's painted landscapes, especially in Otero's treatment of colour and light. On one occasion, Mariana even places the painting of a landscape on an easel in the middle of a meadow; on another, she brings family and friends to the flat in which the family lived for a while and asks her mother's former models to explain and mime how they had posed for her. And last but not least, Clotilde's gestures 
are repeated in front of the camera by the conservationist, as already mentioned, as well as by Mariana's uncle, also a painter.

As for Dieutre, the chiaroscuro sequences in the studio, which seem to mime Caravaggesque bodily gestures, similarly point to a physical involvement with the medium. And physical involvement is to be understood here in the literal sense, for, indeed, both camera and light projector turn around and encircle the protagonists. This involvement enables the film-maker Vincent to come to terms (or at least try to) with his narcissistic crisis and to ascertain his place in the world, as he puts it in the film's opening sequence. Yet, there is perhaps another dimension to these particular sequences. Staged in a studio or dark room, they stand outside the diegesis and come across as visual interludes. Thus isolated, they are comparable to the way in which Gilles Deleuze sees the circle and the oval in Francis Bacon's work: it is about isolating the Figure without compelling it to "immobility but, on the contrary, render sensible a kind of progression, an exploration of the Figure within the place, or upon itself. The relation of the Figure to its isolating place defines a 'fact:' 'the fact is..., 'what takes place is...' Thus isolated, the Figure becomes an Image, an Icon." (Deleuze 2003, 1-2.) To a certain extent, Vincent Dieutre takes Deleuze's point to the letter as he isolates the Caravaggesque Figure, and literally explores its mobility by turning it into a moving image.

Furthermore, Dieutre's formal experimentations with the medium and play with mimesis are also self-reflexive, exploring his status and work as an artist as well as his strategy of using film as a sensory experience. Generally, he tends to resort to different film formats and technologies to organise his narrative structure, in this case, he uses a video, a Super 8 , and a $35 \mathrm{~mm}$ camera. While this aesthetic choice also has narrative implications which will not be developed here, Dieutre explained that varying formats allowed him to achieve a diversity of image textures. The digital camera, which is used for most of the film, gives the image an impression of immediacy and relative closeness to the filmed object because it is handheld, and thus evocative of a journalistic and documentary style for instance: we are physically there with the characters, as it were. The Super 8 is used essentially in the studio scenes and, by contrast with the video and the $35 \mathrm{~mm}$ formats, confers on the images a very distinctive "dirty" grain that echoes the canvas texture and the patina of age characteristic of the $17^{\text {th }}$ century paintings. In fact, the haptic sensation obtained in these sequences through chiaroscuro lighting (as discussed above) is here reinforced by several factors: not only does it enhance tactility through its image quality, but the very materiality of 
the film strip draws attention to matter in general. In addition, because originally designed as an amateur format, the Super 8 format tends to be associated to handicraft. As for the scenes filmed on $35 \mathrm{~mm}$, they correspond to the long static sequences of urban settings. The neat and limpid image quality gives them the appearance of cinematic tableaux, as it were. Moreover, the camera's immobility (notwithstanding the image's own movement) places such sequences at the same level, in narrative terms, as the stills of paintings inserted in the film, for they similarly arouse sensation and provide moments of contemplation. Through this strategy of conspicuously alternating film formats, Dieutre subverts the codes and conventions traditionally attached to each of them, but most importantly, he also shows that their function and significance is not only contextual, but also fully contingent to the historical moment. In other words, the status of such formats shifts and evolves in time and in relation to one another.

\section{Mise en abyme}

If the paintings provide a material and sensory dimension in Dieutre and Otero's films, they also enable the directors/protagonists to stage a mise en abyme of the viewing experience [Figs. 8-9]. Indeed, to watch them looking at the paintings brings the viewers back to their own position as spectators and thus emphasises the reflexive dimension in the art experience in general and in cinema in particular. This is what Vincent Dieutre also refers to when he explains his intention with this film. This is not to posit that the mise en abyme of the spectator position takes place through intermediality exclusively; in any case, cinema abounds in counter-examples of characters watching films within the film and which lead to similar effects. What the interplay with media allows is perhaps a shift in the nature of the viewing experience: it is about questioning our position as spectators in relation to art, but as feeling, rather than understanding spectators, to paraphrase Philippe Dubois for whom the Figural partakes more of seeing and sensing, than of perceiving and understanding (Dubois 1999, 248).

Ágnes Pethő's application of ekphrasis to film is very appropriate here: a film is ekphrastic when the "embedded art form" - in this case the paintings - corresponds, among other things, to the manifestation of "a medium that is different from that of the cinematic image in which it is embedded. In short, an ekphrasis requires the perception of intermedial relations, as 'transformative inscriptions' or 'figurations' of mediality in a work” (Pethő 2010, 213). In Dieutre and Otero's respective film indeed, the paintings are not merely part of the 
diegesis. While they are paramount to the narrative, they are also constitutive of its aesthetics and make the medium conspicuous by contributing to the process of mise en abyme for instance, which ultimately harks back to the broader issue of the cinematic medium. At the same time, the paintings point to materiality: for both film-makers, their personal coming to terms with loss and absence is thus expressed through their film-making and is counterbalanced by a focus on matter, texture and presence.

The body functions here as a sort of sensible interface between the paintings and film. In a way, the body itself is a medium which constitutes an instance of inscription - and even of self-inscription in these specific case studies - of sensations and emotions. Indeed, as Deleuze puts it, "the body is the Figure, or rather, the material of the Figure" (Deleuze 2003, 20). In this sense, the body is the Figure which, in turn, is the mould, in which sensation is inscribed. Suffering and eroticism thus come across as the physical manifestation of such inscriptions, while the cinematic device relies on the haptic gaze to point to materiality and sensory affect. If in-betweenness is considered as a figure of sensation, it certainly applies to intermediality, which, in these specific films, combines the in-betweenness of media with the balance between movement and stillness, between the visibility and invisibility of the gay man, or between the absence and haunting presence of the mother who died in secret.

For Jean-Marie Schaeffer, the body, as it has been represented in Western European culture because of its Christian roots, is embedded in the dialectic relation between matter and abstraction: Christ is the incarnation of God in a human body, hence simultaneously real flesh and image (of God). This explains why we can equally say that "our understanding of the body is an understanding of the image, and our understanding of the image is an understanding of the body" (Schaeffer 2006, 62). In other words, the image is where the body comes to constitute itself. Interestingly enough, Philippe Dubois also reminds us of the paradoxical duality of the Figure which is simultaneously concrete (as imprint, index, etc.) and abstract (as image and icon) (Dubois 1999). In the films discussed here, the body is represented through paintings, it is therefore always already a body as image. At the same time, many elements work towards emphasising the carnal dimension of these bodies, by way of the texture and tactility of the media. In other words, it embodies, so to speak, the tension between abstraction and materiality, which is exactly where cinema lies, that is to say, in the interface between image and reality, between abstraction and concreteness. 


\section{References}

Aumont, Jacques. 2010. L'attrait de la lumière [The Attraction of the Light]. Paris: Éditions Yellow Now.

Balázs, Béla. 2010. Early Film Theory - The Visible Man and The Spirit of Film. New York \& Oxford: Berghahn Books.

Bataille, Georges. 1986 [1957]. Eroticism, Death \& Sensuality. San Francisco: City Lights Books.

Bersani, Leo and Ulysse Dutoit. 1998. Caravaggio's Secrets. Cambridge, MA, \& London: The MIT Press.

Beugnet, Martine. 2007. Cinema and Sensation, French Film and the Art of Transgression. Edinburgh: Edinburgh University Press.

Canguilhem, Georges. 1993 [1966]. Le normal et le pathologique [The Normal and the Pathological]. Paris: PUF. $4^{\text {th }}$ edition.

Deleuze, Gilles. 2003 [1981]. Francis Bacon: The Logic of Sensation. London \& New York: Continuum.

Dubois, Philippe. 1999. L'écriture figurale dans le cinéma muet des années 20 [Figural Writing in the Silent Cinema of the 20s]. In Figure, Figural, eds. François Aubral and Dominique Château, 245-274. Paris: L'Harmattan.

Dyer, Richard. 2002. The Culture of Queers. London \& New York: Routledge.

Kristeva, Julia. 1982 [1980]. Powers of Horror: An Essay on Abjection, trans. Leon S. Roudiez. New York: Columbia University Press.Marks, Laura. 2000. The Skin of Film. Durham \& London: Duke University Press.

Mulvey, Laura. 2006. Death 24x Times a Second. London: Reaktion Books.

Otero, Mariana. 2006. Scénario d'Histoire d'un secret. In Le style dans le cinéma documentaire - Réflexions sur le style, Entretiens et contributions [Style in Documentary Cinema - Reflexions on Style, Interviews and Contributions], eds. Guy Baudon, Anne Baudry, Jean-Louis Baudry [et al], 71-103. Paris: ADDOC/L'Harmattan.

Pethő, Ágnes. 2010. Media in the Cinematic Imagination: Ekphrasis and the Poetics of the In-Between in Jean-Luc Godard's Cinema. In Media Borders, Multimodality and Intermediality, ed. Lars Elleström, 211-222. New York: Palgrave Macmillan Press.

Rancière, Jacques. 2004 [2000]. The Politics of Aesthetics - The Distribution of the Sensible. Translated with an Introduction by Gabriel Rockhill. London \& New York: Continuum. 
Røsaak, Eivind. 2006. Figures of Sensation: Between Still and Moving Images. In The Cinema of Attractions Reloaded, ed. Wanda Strauven, 321-336. Amsterdam: Amsterdam University Press.

Schaeffer, Jean-Marie. 2006. La chair est image [The Flesh is Image]. In Qu'est-ce qu'un corps? [What is a Body?] ed. Stéphane Breton, 58-81. Paris: Flammarion/ Musée du Quai Branly (Exhibition Catalogue.)

The Oxford English Dictionary, $2^{\text {nd }}$ Edition, Volume V. 1991. Oxford: Clarendon Press.

\section{List of Figures}

Figure 1. Partial view of Femme à sa toilette 2 [Woman at Her Toilette 2], Clotilde Vautier's last (unfinished) painting. Histoire d'un Secret (Mariana Otero, 2003). Figure 2. Close-up of Christ's shoulder in Caravaggio's Christ at the Column, Leçons de ténèbres (Vincent Dieutre, 2000). Figure 3. Vincent's body lit by a hand held projector, Leçons de ténèbres (Vincent Dieutre, 2000).
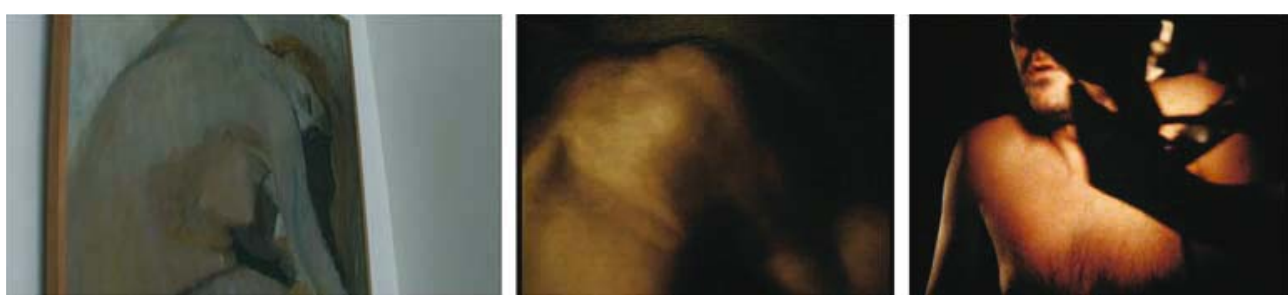

Figure 4. Clotilde's La loge de la comédienne [The Actress's Lodge] filmed in chiaroscuro inside the car in Histoire d'un secret. Figure 5. Close-up of a painting by Clotilde, Histoire d'un Secret.
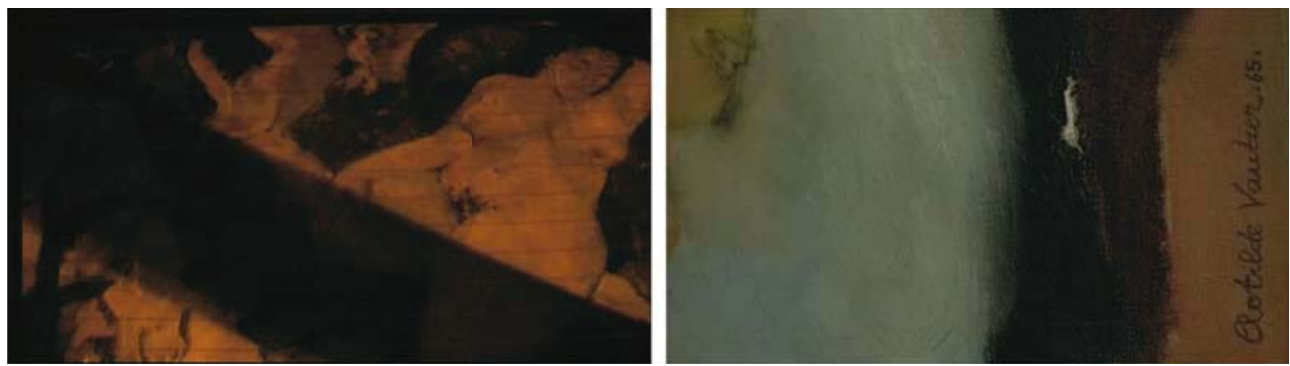
Figure 6. The conservationist examining Clotilde's work, Histoire d'un Secret. Figure 7. Vincent running his hand over his lover's face, Leçons de ténèbres.
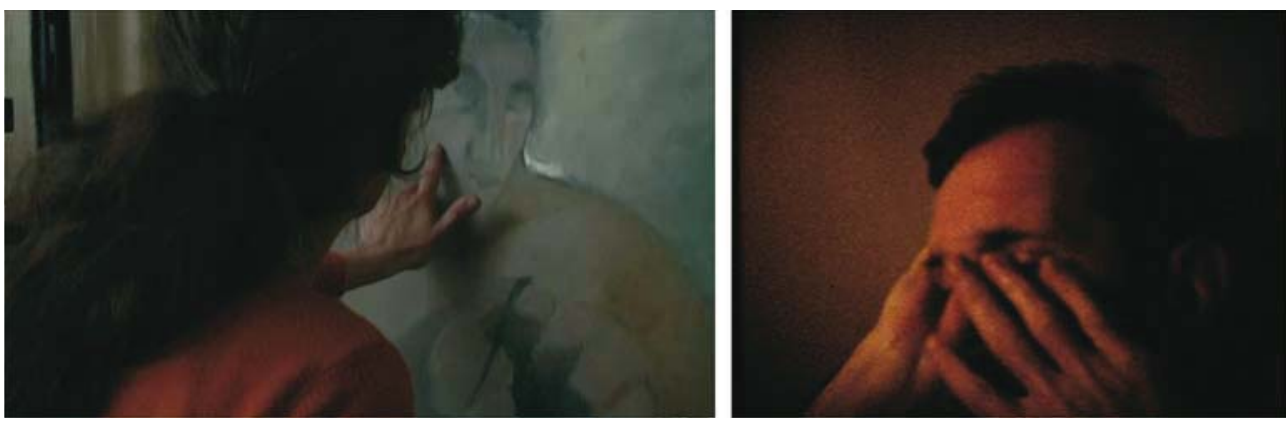

Figure 8. Mariana and her sister looking at one of their mother's paintings in Histoire d'un Secret. Figure 9. Vincent and his partner in front of Jan van Bijlert's Calling of St Matthew (1625-1630), Leçons de ténèbres.
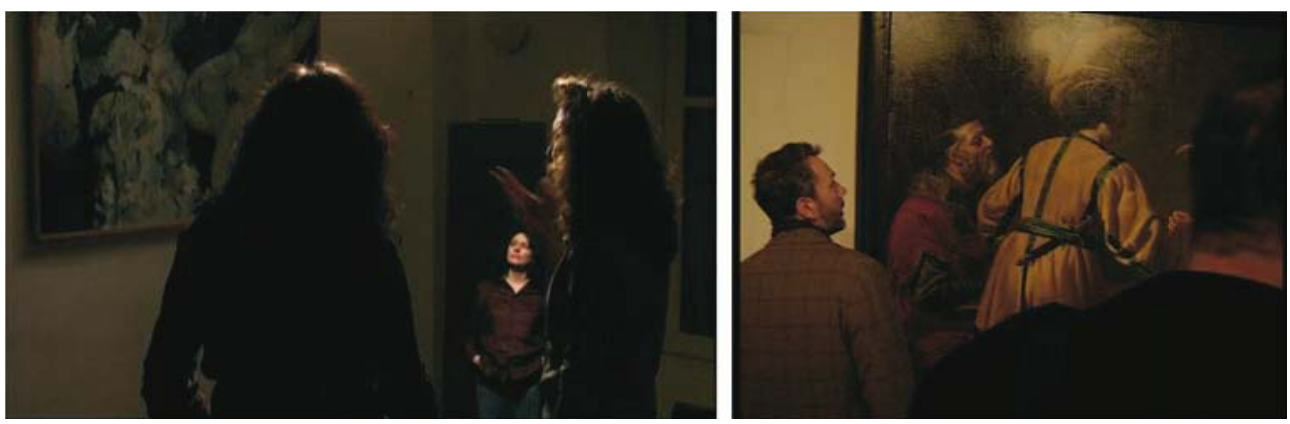